\title{
Effects of HGF gene polymorphisms and protein expression on transhepatic arterial chemotherapeutic embolism efficacy and prognosis in patients with primary liver cancer
}

\author{
This article was published in the following Dove Press journal: \\ OncoTargets and Therapy \\ 13 February 2017 \\ Number of times this article has been viewed
}

\author{
Hai-Yong Chen ${ }^{1,2}$ \\ Yao-Min Chen ${ }^{3}$ \\ Jian $\mathrm{Wu}^{1,2}$ \\ Fu-Chun Yang ${ }^{1,2}$ \\ Zhen $\mathrm{Lv}^{1,2}$ \\ Yi-Gang Qian ${ }^{1,2}$ \\ Shu-Sen Zheng ${ }^{1,2}$ \\ 'Department of Surgery, Division of \\ Hepatobiliary and Pancreatic Surgery, \\ The First Affiliated Hospital, Zhejiang \\ University, ${ }^{2}$ Collaborative Innovation \\ Center for Diagnosis and Treatment \\ of Infectious Diseases, ${ }^{3}$ Department \\ of Breast Surgery, The First Affiliated \\ Hospital, Zhejiang University, \\ Hangzhou, Zhejiang, People's Republic \\ of China
}

Objective: To investigate the correlations of two hepatocyte growth factor $(H G F)$ gene polymorphisms (rs5745652 and rs2074725) and their protein expression levels with the efficacy of transhepatic arterial chemotherapeutic embolism (TACE) and prognosis in patients with primary liver cancer (PLC).

Methods: From March 2011 to June 2012, 109 PLC patients (the case group) who chose TACE as primary treatment and 80 healthy people (the control group) who had undergone physical examination in The First Affiliated Hospital, Zhejiang University were selected during the same period. Gene polymorphisms of $H G F$ rs5745652 and $H G F$ rs2074725 were detected. Serum HGF level, treating efficacy, survival quality, and 3-year survival rate for PLC patients who received TACE were observed.

Results: There were significant differences in genotype and allele frequencies of $H G F$ rs 5745652 and $H G F$ rs 2074725 , between the case and control groups (all $P<0.05$ ). Compared with CT+TT genotype of $H G F$ rs5745652, patients carrying CC genotype had lower serum HGF levels, higher efficacy, better survival quality, and prolonged 3 -year survival rate (all $P<0.05$ ). In rs2074725, patients carrying CA+AA genotype had lower serum HGF levels, higher efficacy, better survival quality, and prolonged 3-year survival rate compared with patients carrying rs2074725 CC genotype (all $P<0.05$ ). Gene polymorphisms of $H G F$ rs5745652 and $H G F$ rs2074725, tumor size, and Barcelona Clinic Liver Cancer stage were independent prognostic factors for PLC $(P<0.05)$.

Conclusion: Our results indicated that $H G F$ gene polymorphisms affect TACE efficacy and survival quality of PLC patients. Patients with HGF CC genotype of rs5745652 and CA+AA genotype of rs2074725 had decreased HGF level, better curative effect, high survival quality, and a good prognosis after TACE treatment.

Keywords: primary liver cancer, hepatocyte growth factor, rs5745652, rs2074725, gene polymorphisms, transhepatic arterial chemotherapeutic embolism efficacy, HGF, TACE efficacy

\section{Introduction}

Primary liver cancer (PLC) is the second most common malignant tumor and leads to 350,000 deaths a year in People's Republic of China. ${ }^{1}$ As the fifth most common cancer in men and the ninth in women, liver cancer is estimated to be the reason for nearly 745,000 deaths in 2012. ${ }^{2}$ The onset of liver cancer is occult and most of the symptoms will not appear until the middle and late stages, thus making it rather difficult to diagnose liver cancer at the early stage. ${ }^{3}$ The main cause of PLC is hepatitis B
Correspondence: Shu-Sen Zheng Hepargery, Division of The First Affiliated Hospital, Zhejiang University, No 79, Qingchun Road, Hangzhou 310000 , Zhejiang, People's Republic of China

Tel +86 57I 87236765

Email zhengshusen@zju.edu.cn (c)
hereby accept the Terms. Non-commercial uses of the work are permitted without any further permission from Dove Medical Press Limited, provided the work is properly attributed. For permission hereby accept the Terms. Non-commercial uses of the work are permitted without any further permission from Dove Medical Press Limited, provided the work is properly attributed. For permission 
virus and hepatitis $\mathrm{C}$ virus infection, and aflatoxin, alcohol intake, smoking, obesity, and diabetes. ${ }^{4}$ Because of the disease severity or the rarity of suitable organ donors at the time of diagnosis, only a minority of subjects can be treated by the potentially effective therapies such as liver transplantation and surgical resection. ${ }^{5}$ Moreover, due to tumor size and tumor numbers, it is also difficult to apply surgical removal; therefore, transhepatic arterial chemotherapeutic embolism (TACE), a minimally invasive treatment, is the main therapeutic method for patients suffering from liver cancer. ${ }^{6}$ After TACE therapy, tumor markers are needed to predict the prognosis of patients with liver cancer. ${ }^{7}$

Hepatocyte growth factor (HGF), also known as scatter factor, is a multifunctional growth factor and mesenchymederived cytokine with potent neurotrophic, angiogenic, and antiapoptotic effects. ${ }^{8}$ Through the activation of HGF-Met pathway, it can affect tumorigenesis and tumor invasion, and promote the growth, regeneration, and morphogenesis of various types of tissues and cells. ${ }^{9}$ The activation and overexpression of autocrine $H G F$ in cancer cells are considered to be a contributory factor for tumor formation and growth. ${ }^{10}$ Evidence showed that the high expressions of HGF mRNA and protein in breast cancer tissue were associated with poor survival rate. ${ }^{11}$ In addition, another study pointed out that the activity of HGF affects dissemination and ascite formation and HGF secreted by ovarian cancer cells plays an important role in cancer peritoneal implantation. ${ }^{12}$ However, researches about, whether, and how $H G F$ gene polymorphisms (rs5745652 and rs2074725) and its protein expression level affect the efficacy of TACE and survival of PLC are still very scarce. Therefore, this paper intends to assess the correlations of efficacy of TACE therapy with HGF gene polymorphisms (rs5745652 and rs2074725) in patients with PLC.

\section{Materials and methods Ethics statement}

This study was approved by the Ethics Committee of The First Affiliated Hospital, Zhejiang University, and written informed consent was obtained from each patient or guardians prior to study.

\section{Research subjects}

From March 2011 to June 2012, a total of 109 PLC patients were recruited from The First Affiliated Hospital, Zhejiang University who chose TACE as primary treatment (case group, $n=109)$. There were 95 male and 14 female aging 25-76 years (52.27 \pm 5.21 years). According to Child-Pugh class, ${ }^{13}$ the patients in case group were classified into: class A, 16 cases and class B, 93 cases. Based on Barcelona Clinic
Liver Cancer (BCLC) staging classification, ${ }^{14}$ there were 53 cases in stage B and 56 cases in stage C. In terms of the diameter of the tumor, 36 cases were $\leq 5 \mathrm{~cm}$ and 73 cases were $>5 \mathrm{~cm}$. Besides, 47 cases undergone $\leq 4$ times of TACE treatment and 62 cases $>4$ times. Inclusion criteria were as follows: 1) patients were diagnosed with PLC based on American Association for the Study of Liver Diseases (AASLD); ${ }^{15}$ 2) expected survival time $>3$ months; 3 ) primary treatment was TACE; 4) patients could obtain at least one TACE treatment; 5) volunteer to participate in this research. Exclusion criteria: 1) patients have other malignant tumors or complication with serious chronic diseases; 2) pregnant or breast-feeding women; 3 ) patients have TACE treatment contraindications or allergic to contrast agent; 4) patients have severe liver dysfunction, active bleeding tendency or severe coagulation disorders; 5) patients refuse to participate in the research. All patients in the study met the inclusion criteria. Meanwhile, 80 healthy people undergone physical examination in our hospital during the same period were selected as control group, including 69 males and 11 females, aging 22-74 years ( $51.63 \pm 6.94$ years). The inclusion criteria for the control group are as follows: 1) no history of cancer; 2) no siblingship with patients in case group; 3) volunteer to participate in the study. There was no significant difference in gender or age between the two groups (both $P>0.05$ ).

\section{Sample collection}

After fasting for $12 \mathrm{~h}$, all subjects were extracted with $8 \mathrm{~mL}$ of peripheral venous blood the next morning. Half of the blood samples were anticoagulated with ethylenediaminetetraacetic acid. After conventional even mixing, the whole blood samples were temporarily stored in refrigerator at $4^{\circ} \mathrm{C}$. Whole-genome DNA kit (Shanghai SaiBaiSheng Bioengineering Co., Ltd., Shanghai, People's Republic of China) was used for extraction of blood samples in accordance with the instruction. The other half samples were placed at room temperature for $2 \mathrm{~h}$ before $10 \mathrm{~min}$ of $3,000 \mathrm{rpm} / \mathrm{min}$ centrifugation. Then the supernatant was stored at $-80^{\circ} \mathrm{C}$, which was used for the detection of serum HGF protein levels.

The serum HGF protein level was detected before and after TACE treatment. The serum HGF protein was measured by double antibody sandwich enzyme-linked immunosorbent assay. Kits were purchased from Rapdbio Company (San Diego, CA, USA) and the operation procedures in strict accordance with the instructions.

\section{Genotyping}

Polymerase chain reaction (PCR) restriction fragment length polymorphism was used to detect the polymorphism of $H G F$ 
rs5745652. Primers were designed as follows: upstream 5'-CACGTAGGCTGGAACTGAGT-3'; downstream 5'-ACAGCATTCCAGTA-GTCCCC-3'. PCR primers were designed and synthesized by Takara Biotechnology Co., Ltd.; Dalian, People's Republic of China. PCR amplification was applied to whole-genome DNA, extracted from blood samples. PCR amplification reaction system includes: double-distilled water $\left(\mathrm{ddH}_{2} \mathrm{O}\right) 17.5 \mu \mathrm{L}$, upstream primer $0.5 \mu \mathrm{L}$, downstream primer $0.5 \mu \mathrm{L}$, Taq DNA polymerase $0.125 \mu \mathrm{L}$, deoxy-nucleotide-tri phosphate 2 (dNTP 2) $\mu \mathrm{L}$, $10 \times$ ESTaq slow release liquid $2.5 \mu \mathrm{L}$, and DNA $1 \mu \mathrm{L}$. PCR reaction conditions: pre-denaturation for $5 \mathrm{~min}$ at $95^{\circ} \mathrm{C}$, then a total of 36 cycles of denaturation for $30 \mathrm{~s}$ at $95^{\circ} \mathrm{C}$, annealing for $45 \mathrm{~s}$ at $56^{\circ} \mathrm{C}$, extending for $1 \mathrm{~min}$ at $72^{\circ} \mathrm{C}$, and at last extending for $5 \mathrm{~min}$ at $72^{\circ} \mathrm{C}$. Conditions for PCR product restriction enzyme reaction were $\mathrm{ddH}_{2} \mathrm{O} 1.0 \mu \mathrm{L}, 10 \times$ buffer $1.0 \mu \mathrm{L}, 10 \mu \mathrm{g} / \mu \mathrm{L}$ bovine serum albumin $0.5 \mu \mathrm{L}$, template $7 \mu \mathrm{L}$, and $H p a \mathrm{II}$ endonuclease $0.5 \mu \mathrm{L}$. After being placed into thermostat at $37^{\circ} \mathrm{C}$ for a night, products of restriction enzyme digestion were analyzed with $3 \%$ agarose gel electrophoresis.

Polymorphism of $H G F$ rs2074725 was detected by single allele-specific primer (SASP-PCR). The primer sequences are as follows: upstream primer P1-C (wild): 5'-CAAATTATAGTCCAGAGCTTACC-3'; P1-A (mutant): 5'-CAAATTATAGTCCAGAGCTTACA-3'; downstream primer P2: 5'-TCTTGTGCCAAAACGAAAC-3'. PCR primers were designed and synthesized by Takara Biotechnology (Dalian) Co., Ltd. PCR reaction: two PCR reactions are needed to detect the gene type of every research object, one reaction using P1-C and the other P1-A with all other conditions the same. PCR total volume is $20 \mu \mathrm{L}$ with dNTP $1 \mu \mathrm{L}, 10 \times$ buffer $2 \mu \mathrm{L}$, Taq enzyme $0.2 \mu \mathrm{L}$ DNA, primers each $1 \mu \mathrm{L}$. PCR amplification was performed after short-time centrifugation. PCR reaction conditions: pre-denaturation for $5 \mathrm{~min}$ at $94^{\circ} \mathrm{C}$, then denaturation for $40 \mathrm{~s}$ at $94^{\circ} \mathrm{C}$, annealing for $40 \mathrm{~s}$ at $56^{\circ} \mathrm{C}$, extending for $1 \mathrm{~min}$ at $72^{\circ} \mathrm{C}$, for a total of 35 cycles, and at last extending for 10 times at $72^{\circ} \mathrm{C}$ before being stored at $4{ }^{\circ} \mathrm{C}$. Seven percent agarose gel electrophoresis was used as amplifier, ethidium bromide was used for staining, and electrophoresis results were detected under ultraviolet light. Experimental reagents were all purchased from Shanghai Bioleaf Biotech Co., Ltd. (Shanghai, People's Republic of China).

\section{TACE regimens}

The right femoral artery of patients was punctured and conventional skin disinfection was performed. The percutaneous transarterial access to the hepatic artery or its branches was obtained through Seldinger technique. Hepatic artery angiography was performed to identify the proper hepatic artery supplying the tumor. Then microcatheter was sent into the blood supplying artery to inject 40-60 mg cisplatin, 6-10 mg mitomycin $\mathrm{C}$, and $1,000 \mathrm{mg}$ fluorouracil per square meter of body surface area, and the mixture of $30 \mathrm{mg}$ pirarubicin and $8-20 \mathrm{~mL}$ of $40 \%$ iodized oil was injected per square meter of body surface area. Gelatin sponge embolization of the target artery was the last step of the TACE treatment. The treatment was performed every 4-6 weeks. The reagents used in the experiment were purchased from Sangon Biotech Co., Ltd. (Shanghai, People's Republic of China).

\section{Efficacy criteria of TACE}

The curative effect of TACE therapy for PLC was evaluated according to the response evaluation criteria in solid tumors. ${ }^{16}$ Complete response (CR) means that liver tumor disappears without new lesions occurred, and tumor markers are normal for at least 4 weeks. Partial response (PR) means that the decrease in the sum of the longest diameter (LD) of liver tumor is over 30\% for at least 4 weeks. Stable disease (SD) means that the decrease in the sum of the LD of the liver tumor was not up to PR or the increase was not up to Progress disease (PD). PD means that the increase in the sum of the LD of the liver tumor is at least $20 \%$, or new lesions appear. Effective includes $\mathrm{CR}$ and $\mathrm{PR}$ and ineffective includes SD and PD.

\section{Follow-up}

All patients were followed-up for 3 years until December 31, 2015. Life quality of patients was observed and Karnofsky score ${ }^{17}$ was used to evaluate the survival quality of patients before and after treatment and 3 months after treatment. The survival time and 3-year survival rate of the patients were observed. Calculation criterion of survival time is taken from treatment ending to the last follow-up or patients' death.

\section{Statistical analysis}

The statistical analyses were conducted with SPSS Version 21.0 (SPSS Inc., Chicago, IL, USA). Measurement data presented by $\overline{\mathrm{x}} \pm \mathrm{s}$ were compared using an unpaired $t$-test. Categorical data presented by ratio or percentage were compared by chi-square test. Chi-square goodness-of-fit test used to confirm whether genotype distribution in the control group is consistent with the Hardy-Weinberg equilibrium or not. Kaplan-Meier estimator was used to analyze survival quality, and survival time was compared using log-rank test. $P$-value was two-tailed test and $<0.05$ was considered statistically different. 


\section{Results}

\section{Electrophoresis results of PCR products}

The PCR products were digested by restriction enzyme HpaII and polymorphism was detected in $H G F$ gene rs5745652 (Figure 1A). Gene typing was performed according to the electrophoresis results of enzyme digestion products. The enzyme digestion products of HGF rs5745652 gene included gene fragments of 541, 417, and $123 \mathrm{bp}$, which were mutant heterozygous CT; gene fragments of 252 and $124 \mathrm{bp}$, which were mutant homozygous CC; gene fragment of $376 \mathrm{bp}$, which was wild-type homozygous TT. SASP-PCR results showed the existence of polymorphism at rs2074725 site of $H G F$ gene. The 1, 3, and 5 lanes were the electrophoresis results of PCR with the addition of P1-C primer, and the 2, 4, and 6 lanes were the electrophoresis results of PCR with the addition of $\mathrm{P} 1-\mathrm{A}$ primer, including wild type $\mathrm{CC}$ ( 5 and 6 lanes), mutant heterozygous CA (1 and 2 lanes), and mutant homozygous AA (3 and 4 lanes) (Figure 1B).

\section{Distribution of genotype and allele frequencies of two HGF gene polymorphisms}

Both in the control group and the case group, rs5745652 and rs2074725 of HGF gene achieved Hardy-Weinberg genetic equilibrium in terms of polymorphism genotype and allele frequency distribution. Table 1 shows the TT genotype, CT genotype, CC genotype, and allele frequency of $H G F$ gene rs5745652 in case group were significantly different from those in the control group (all $P<0.05$ ), and allele $\mathrm{C}$ was a protective gene $(P<0.001$, odds ratio $[\mathrm{OR}]=0.338$, 95\% confidence interval [CI]: 0.207-0.553). The CC genotype, CA genotype, AA genotype, and allele frequency of $H G F$ gene rs2074725 in the case group were significantly different from those in the control group (all $P<0.05$ ), and allele A was a protective gene $(P<0.001, \mathrm{OR}=0.301,95 \%$ CI: 0.181-0.502).

\section{Serum HGF protein level changes of two HGF gene polymorphisms before and after treatment}

The changes of serum HGF protein level in the patients of different $H G F$ genotype before and after treatment are shown in Table 2. The pretreatment serum HGF protein levels in patients carrying different genotypes of $H G F$ gene rs 5745652 and rs2074725 were not different from posttreatment levels (both $P>0.05$ ), and HGF levels of all patients were significantly reduced after treatment compared with before treatment (all $P<0.05$ ). CT genotype at $H G F$ rs5745652 was too few in number, so we combined genotype CT and TT as CT+TT genotype. After treatment, the serum HGF level of CC genotype was significantly lower than that of CT+TT genotype $(P<0.05)$. Since AA genotype at $H G F$ rs 2074725 was also too few in number, we combined AA and CA genotypes as $\mathrm{CA}+\mathrm{AA}$ genotype. After treatment, the serum HGF level of $\mathrm{CA}+\mathrm{AA}$ genotype was significantly lower than that of CC genotype $(P<0.05)$ (Table 2$)$.

\section{Comparisons of TACE curative effect of each HGF genotype between the case and control groups}

Three months after treatment, 36 cases of patients with $H G F$ rs5745652 CC genotype were effective with a total efficacy rate of $78.26 \%$ and 26 cases of CT+TT genotype were effective with a total efficacy rate of $41.27 \%$, indicating that in terms of treatment efficacy, patients carrying CT+TT genotype were much lower than those carrying CC genotype
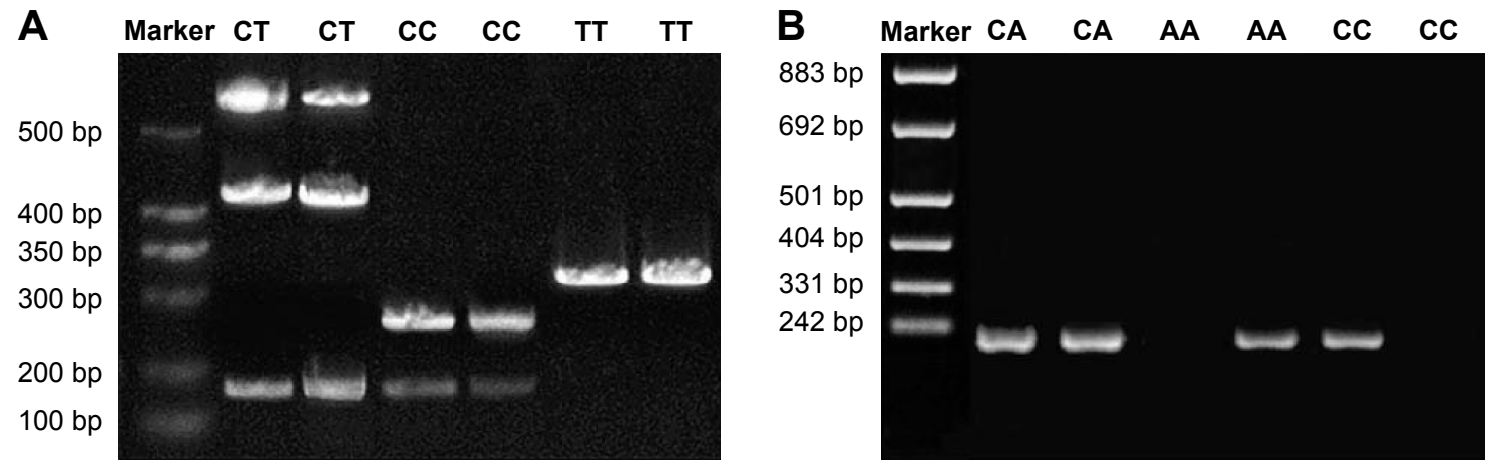

Figure I Enzyme digestion results of rs5745652 and rs2074725 sites of the HGF gene.

Notes: (A) Enzyme digestion results of the rs5745652 site; (B) enzyme digestion results of the rs2074725 site.

Abbreviation: HGF, hepatocyte growth factor. 
Table I Distribution of genotype and allele frequencies of two HGF gene polymorphisms in the case and control groups

\begin{tabular}{|c|c|c|c|c|}
\hline SNPs & Control group $(n=80)$ & Case group $(n=109)$ & $P$-value & OR $(95 \% \mathrm{Cl})$ \\
\hline \multicolumn{5}{|c|}{ rs5745652 } \\
\hline TT & $2(2.5)$ & $21(19.3)$ & Reference & \\
\hline CT & $24(30.0)$ & $42(38.5)$ & 0.012 & $0.167(0.036-0.777)$ \\
\hline $\mathrm{CC}$ & $54(67.5)$ & $46(42.2)$ & $<0.00 \mathrm{I}$ & $0.081(0.018-0.365)$ \\
\hline $\mathrm{T}$ & $28(17.5)$ & $84(38.5)$ & Reference & \\
\hline C & $132(82.5)$ & $134(6 \mid .5)$ & $<0.001$ & $0.338(0.207-0.553)$ \\
\hline \multicolumn{5}{|c|}{ rs2074725 } \\
\hline $\mathrm{CC}$ & $36(45.0)$ & $84(77.1)$ & Reference & \\
\hline $\mathrm{CA}$ & $34(42.5)$ & $22(20.2)$ & 0.001 & $0.277(0.143-0.538)$ \\
\hline AA & $10(12.5)$ & $3(2.8)$ & 0.001 & $0.129(0.033-0.495)$ \\
\hline C & $106(66.3)$ & $189(86.7)$ & Reference & \\
\hline A & $54(33.7)$ & $29(13.3)$ & $<0.001$ & $0.30 I(0.18 I-0.502)$ \\
\hline
\end{tabular}

Note: Data presented as n (\%).

Abbreviations: $\mathrm{Cl}$, confidence interval; HGF, hepatocyte growth factor; SNPs, single nucleotide polymorphisms; OR, odds ratio.

$(P<0.05)$. When it comes to the $H G F$ rs2074725, 20 cases of $\mathrm{CA}+\mathrm{AA}$ genotype were effective with a total efficacy rate of $80.00 \%$ and 42 cases of CC genotype were effective with a total efficacy rate of $50.00 \%$, which demonstrated that the total treatment efficacy in patients carrying CC genotype was much lower than those carrying $\mathrm{CA}+\mathrm{AA}$ genotype $(P<0.05)$ (Table 3)

\section{Comparisons of survival quality of each HGF genotype between the case and control groups}

As shown in Table 4, there was no significant difference in the Karnofsky scores before and after the treatment on different $H G F$ genotype $(P>0.05)$. Three months after TACE treatment, patients carrying $\mathrm{CC}$ genotype at $H G F$ rs5745652 or CA+AA genotype at $H G F$ rs2074725 got higher Karnofsky score than before treatment $(P<0.05)$. Patients of CC genotype had higher Karnofsky score than those of CT+TT genotype at $H G F$ rs5745652, and patients of CA+AA genotype had higher Karnofsky score than those of CC genotype at $H G F$ rs2074725 (all $P<0.05$ ).

Table 2 Serum HGF protein level changes of each HGF genotypes before and after treatment between the case and control groups

\begin{tabular}{llll}
\hline SNP & Cases & \multicolumn{1}{l}{ HGF $(\mathrm{pg} / \mathrm{mL})$} & \\
\cline { 3 - 4 } & & Before & After \\
\hline rs5745652 & & $1,422.16 \pm 137.17$ & $\mathrm{I}, 115.92 \pm 67.07^{\mathrm{a}}$ \\
CT+TT & 63 & $1,425.07 \pm 159.65$ & $\mathrm{I}, 002.87 \pm\left. 113.9\right|^{\mathrm{a}, \mathrm{b}}$ \\
CC & 46 & & \\
rs2074725 & & $1,435.37 \pm 142.25$ & $\mathrm{I}, 109.19 \pm 75.09^{\mathrm{a}}$ \\
CC & 84 & $1,383.10 \pm 155.67$ & $930.52 \pm 70.60^{\mathrm{a}, \mathrm{c}}$ \\
CA+AA & 25 &
\end{tabular}

Notes: a Compared with before treatment, $P<0.05$, b ${ }^{b}$ compared with rs574565 $\mathrm{CT}+\mathrm{TT}$ genotype, $P<0.05$, 'compared with rs 2074725 CC genotype, $P<0.05$. Abbreviations: HGF, hepatocyte growth factor; SNP, single nucleotide polymorphism.

\section{Analysis of HGF rs5745652 polymorphism and the survival rate of patients with PLC}

All patients were followed-up by telephone or regular outpatient follow-up and the last follow-up was conducted on July 30, 2015. Survival curves of patients carrying CT+TT genotype or CC genotype at rs5745652 site of $H G F$ are shown in Figure 2A. Patients carrying CC genotype at $H G F$ rs 5745652 had a 3 -year survival rate of $30.43 \%$ (14/46), while patients carrying $\mathrm{CT}+\mathrm{TT}$ genotype at $H G F$ rs 5745652 had a 3-year survival rate of $6.35 \%(4 / 63)$, indicating that patients with $\mathrm{CC}$ genotype had higher 3-year survival rate than $\mathrm{CT}+\mathrm{TT}$ genotype in this aspect $(P<0.05)$. Patients carrying CA+AA genotype at $H G F$ rs 2074725 had a 3-year survival rate of $44.00 \%$ (11/25), which was significantly higher than those carrying $C C$ genotype at $H G F$ rs2074725 of $8.00 \%(7 / 84)(P<0.05)$ (Figure $2 \mathrm{~B})$.

\section{Cox regression analyses}

Factors included in the Cox proportional risk model were $H G F$ rs5745652 and $H G F$ rs2074725, age, gender, tumor size, BCLC stage, and TACE treatment frequency. The results showed that rs5745652 and rs2074725 polymorphisms,

Table 3 Comparisons of TACE curative effect of each HGF genotypes between the case and control groups

\begin{tabular}{llllll}
\hline SNP & Cases & Effective & Ineffective & $\begin{array}{l}\text { Total efficacy } \\
\text { rate (\%) }\end{array}$ & P-value \\
\hline rs5745652 & & & & & 0.012 \\
CT+TT & 63 & 26 & 37 & 41.27 & \\
CC & 46 & 36 & 10 & 78.26 & \\
rs2074725 & & & & & 0.008 \\
CC & 84 & 42 & 42 & 50.00 & \\
CA+AA & 25 & 20 & 5 & 80.00 & \\
\hline
\end{tabular}

Abbreviations: HGF, hepatocyte growth factor; SNP, single nucleotide polymorphism; TACE, transcatheter arterial chemoembolization. 
Table 4 Comparisons of survival quality of each HGF genotypes between the case and control groups

\begin{tabular}{lllll}
\hline SNPs & Case & Before & After & 3-month follow-up \\
\hline rs5745652 & & & & \\
CT+TT & 63 & $59.88 \pm 13.33$ & $59.35 \pm 9.66$ & $69.57 \pm 10.47^{\mathrm{a}}$ \\
CC & 46 & $63.38 \pm 10.88$ & $63.39 \pm 10.28$ & $76.28 \pm 9.33^{\mathrm{a}, \mathrm{b}}$ \\
rs2074725 & & & & \\
CC & 84 & $60.85 \pm 13.17$ & $60.27 \pm 9.99$ & $70.67 \pm 10.52^{\mathrm{a}}$ \\
CA+AA & 25 & $63.07 \pm 9.53$ & $63.71 \pm 10.11$ & $78.19 \pm 8.27^{\mathrm{a}, \mathrm{c}}$ \\
\hline
\end{tabular}

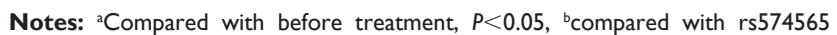
$\mathrm{CT}+\mathrm{TT}$ genotype, $P<0.05$, 'compared with rs $2074725 \mathrm{CC}$ genotype, $P<0.05$. Data presented as mean \pm standard deviation.

Abbreviations: SNPs, single nucleotide polymorphisms; HGF, hepatocyte growth factor.

tumor size, and BCLC stage were independent factors for prognosis of patients with PLC (all $P<0.05$ ) (Table 5).

\section{Discussion}

It was reported that genetic change and expression change accordingly can affect the malignant progression and prognosis of tumors. ${ }^{18,19}$ Therefore, study on the relation of $H G F$ gene polymorphisms with TACE efficacy and survival has great significance. This study proved that $H G F$ polymorphisms affect the efficacy of TACE and survival quality of PLC patients. Patients carrying HGF CC genotype of rs5745652 or CA+AA genotype of rs2074725 have lower HGF level, better curative effect, higher survival quality, and better prognosis after treatment.

In this study, we found that the allele C of $H G F$ rs 5745652 and the A allele of the $H G F$ rs2074725 are protective genes. $H G F$ is a kind of multifunctional and heterogeneous polypeptide produced by mesenchymal cells and it can mediate the growth and dispersion of different types of

A

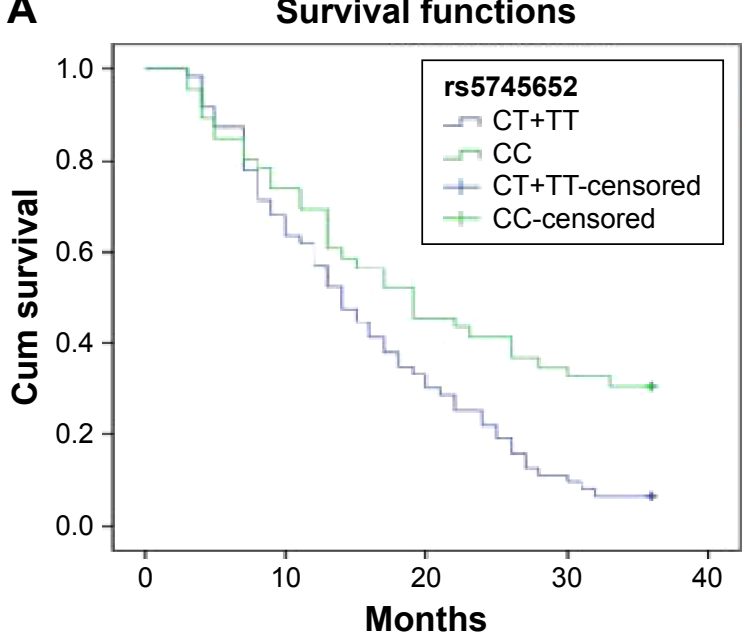

cells. ${ }^{20} H G F$ can promote the generation of new blood vessels in tumors through activation mechanism and create conditions for the growth and transfer of tumor. ${ }^{21,22}$ Evidence has shown that patients with liver cancer had significantly higher serum HGF levels than those without liver cancer. ${ }^{23}$ HGF and its receptor c-Met will form a paracrine signaling cycle to mediate the development and progression of cancers. ${ }^{24} \mathrm{~A}$ study has confirmed that upregulated expression of growth factors, including $H G F$, and the activation of their signaling pathway play an important role in the formation of liver cancer. ${ }^{25}$ Another study noted that the " $\mathrm{A}$ " allele is a protective gene, which is consistent with the result of this paper. ${ }^{26}$ Besides, a previous study has demonstrated that the function of the spleen is deteriorating and serum HGF protein levels can be elevated in patients with liver cirrhosis due to overexpression of HGF protein by the spleen.$^{27}$ Furthermore, patients with chronic hepatitis $\mathrm{C}$ have also proved that higher HGF concentrations were correlated with increased fibrosis and angiogenesis and have indicated a higher risk of PLC development. ${ }^{28-31}$

In this study, we found that the serum HGF level in patients carrying rs5745652 CC genotype was significantly lower than those carrying the CT+TT genotype, and the total efficacy rate of patients carrying CC genotype was significantly higher than those carrying CT+TT genotype. Serum HGF level of patients carrying rs2074725 CA+AA genotype was significantly lower than those carrying the CC genotype, and the total efficacy rate of $\mathrm{CA}+\mathrm{AA}$ genotype patients was significantly higher than those carrying the CC genotype. It has been demonstrated that HGF levels were higher in cancer cell lines than in normal hepatocyte cell lines, and

B

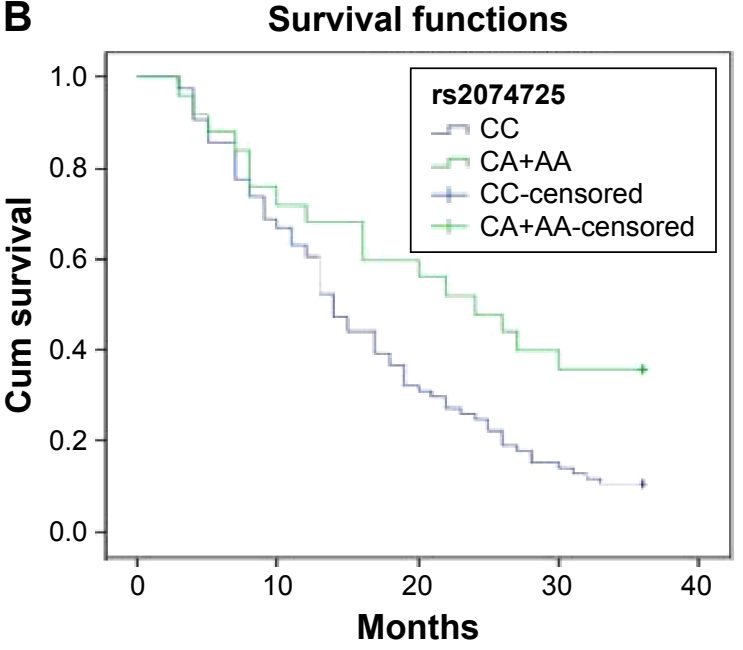

Figure 2 Kaplan-Meier survival functions.

Notes: (A) Survival functions of each rs5745652 genotype; (B) survival functions of each rs2074725 genotype. 
Table 5 Cox regression analysis of prognostic factors of PLA TACE therapy

\begin{tabular}{llllll}
\hline Factor & B & SE & Wald & P-value & OR $(95 \%$ CI $)$ \\
\hline rs5745652 site & -0.592 & 0.268 & 4.894 & 0.027 & $0.553(0.327-0.935)$ \\
rs2074725 site & -0.827 & 0.289 & $8.18 \mathrm{I}$ & 0.004 & $0.438(0.248-0.77 \mathrm{I})$ \\
BCLC stage & $\mathrm{I} .206$ & 0.339 & 12.638 & $<0.00 \mathrm{I}$ & $3.339(\mathrm{I} .718-6.492)$ \\
Tumor size & 0.719 & 0.310 & 5.387 & 0.020 & $2.052(\mathrm{I} .1 \mathrm{I}-3.767)$ \\
TACE frequency & -0.367 & 0.298 & 1.521 & 0.217 & $0.693(0.386-1.242)$ \\
Gender & 0.553 & 0.365 & 2.286 & $0.13 \mathrm{I}$ & $\mathrm{I} .738(0.849-3.557)$ \\
Age & 0.005 & 0.021 & 0.050 & 0.823 & $1.005(0.964-\mathrm{I} .048)$ \\
\hline
\end{tabular}

Abbreviations: $\mathrm{Cl}$, confidence interval; $\mathrm{BCLC}$, Barcelona Clinic Liver Cancer; OR, odds ratio; PLA, primary liver cancer; SE, standard error; TACE, transcatheter arterial chemoembolization.

HGF upregulation can directly promote the mesenchymal and tumorigenic properties in liver cancer through the activation of Akt and COX-2 pathways. ${ }^{32}$ Therefore, serum HGF increase may implicate in the occurrence and progression of liver cancer. A study has shown that the transcription activity of $H G F-1652 \mathrm{~T}$ allele was less than that of $\mathrm{C}$ allele so TT genotype carriers were more likely to get end-stage liver disease (ESLD) than CT or CC genotype carriers, and accordingly the total efficacy rate of $\mathrm{T}$ genotype carriers will be lower. ${ }^{33} \mathrm{~A}$ research by Motone et al showed that serum HGF level in rs2074725 CC genotype carriers was much higher than that in CA or AA genotype carriers and the liver $H G F$ secretion of $\mathrm{CC}$ genotype carriers increased indicating that the total efficacy rate of TACE therapy will be lower in $\mathrm{CC}$ genotype carriers than in $\mathrm{CA}+\mathrm{AA}$ genotype carriers. ${ }^{34}$

The study found that the Karnofsky scores of patients carrying $H G F$ rs5745652 CC genotype or carrying $H G F$ rs2074725 CA+AA genotype were significantly enhanced than before TACE treatment, and they were higher than those of counterpart CT+TT genotype or CC genotype carriers, respectively. The 3-year survival rates of the former two were also higher than that of the latter ones. Chemoembolization is an important therapy for patients with liver cancer, and the continuous elevation of serum HGF level after TACE may be associated with the postoperative tumor metastasis. ${ }^{32}$ Serum HGF level, as an important tumor marker, is closely related to metastasis and recurrence of some tumors, and high HGF level is not beneficial to the prognosis. ${ }^{35-37}$ Therefore, with a relatively low serum HGF level, rs5745652 CC genotype and rs2074725 CA+AA genotype are conducive to the treatment of PLC and the improvement of patients' survival rate.

This study pointed out that the $H G F$ gene polymorphisms can influence the efficacy of TACE and survival quality of PLC patients. Specifically, the HGF level of patients carrying
$H G F \mathrm{CC}$ genotype of rs5745652 or HGF CA+AA genotype of rs2074725 was decreased after TACE, which was related to superior curative effect, survival quality, and prognosis. However, the mechanism of how $H G F$ gene rs5745652 site and rs2074725 affect the occurrence, development, and prognosis of PLC has not been clarified, and follow-up study is still needed.

\section{Acknowledgment}

We would like to acknowledge the helpful comments on this paper received from our reviewers.

\section{Disclosure}

The authors report no conflicts of interest in this work.

\section{References}

1. Chen JG, Zhang SW. Liver cancer epidemic in China: past, present and future. Semin Cancer Biol. 2011;21(1):59-69.

2. Ferlay J, Soerjomataram I, Dikshit R, et al. Cancer incidence and mortality worldwide: sources, methods and major patterns in GLOBOCAN 2012. Int J Cancer. 2015;136(5):E359-E386.

3. Pircher A, Medinger M, Drevs J. Liver cancer: targeted future options. World J Hepatol. 2011;3(2):38-44.

4. Fan JH, Wang JB, Jiang Y, et al. Attributable causes of liver cancer mortality and incidence in china. Asian Pac J Cancer Prev. 2013;14(12): 7251-7256.

5. Hernandez-Alcoceba R, Sangro B, Prieto J. Gene therapy of liver cancer. Ann Hepatol. 2007;6(1):5-14.

6. Loffroy R, Favelier S, Cherblanc V, Estivalet L. C-arm dual-phase cone-beam CT: a revolutionary real-time imaging modality to assess drug-eluting beads TACE success in liver cancer patients. Quant Imaging Med Surg. 2013;3(4):196-199.

7. Zhang J, Jiang TY, Jiang BG, et al. RMP predicts survival and adjuvant TACE response in hepatocellular carcinoma. Oncotarget. 2015 ; 6(5):3432-3442.

8. Kessler JA, Smith AG, Cha BS, et al. Double-blind, placebo-controlled study of HGF gene therapy in diabetic neuropathy. Ann Clin Transl Neurol. 2015;2(5):465-478.

9. Sakai K, Aoki S, Matsumoto K. Hepatocyte growth factor and Met in drug discovery. J Biochem. 2015;157(5):271-284.

10. Petrini I. Biology of MET: a double life between normal tissue repair and tumor progression. Ann Transl Med. 2015;3(6):82.

11. Ma J, DeFrances MC, Zou C, Johnson C, Ferrell R, Zarnegar R. Somatic mutation and functional polymorphism of a novel regulatory element in the HGF gene promoter causes its aberrant expression in human breast cancer. J Clin Invest. 2009;119(3):478-491.

12. Nakamura M, Ono YJ, Kanemura M, et al. Hepatocyte growth factor secreted by ovarian cancer cells stimulates peritoneal implantation via the mesothelial-mesenchymal transition of the peritoneum. Gynecol Oncol. 2015;139(2):345-354.

13. Helling G, Wahlin S, Smedberg M, et al. Plasma glutamine concentrations in liver failure. PLoS One. 2016;11(3):e0150440.

14. Llovet JM, Bru C, Bruix J. Prognosis of hepatocellular carcinoma: the BCLC staging classification. Semin Liver Dis. 1999;19(3):329-338.

15. Bruix J, Sherman M; Practice Guidelines Committee, American Association for the Study of Liver Diseases. Management of hepatocellular carcinoma. Hepatology. 2005;42(5):1208-1236.

16. Eisenhauer EA, Therasse P, Bogaerts J, et al. New response evaluation criteria in solid tumours: revised RECIST guideline (version 1.1). Eur J Cancer. 2009;45(2):228-247. 
17. Apostolopolou E, Raftopoulos V, Terzis K, Pissaki K, Pagoni M, Delibasi S. Infection probability score, apache ii and karnofsky scoring systems as predictors of infection onset in haematology-oncology patients. J Clin Nurs. 2010;19(11-12):1560-1568.

18. Liu $\mathrm{Y}, \mathrm{Hu} \mathrm{H}$, Zhang $\mathrm{C}$, et al. Co-expression of mitosis-regulating genes contributes to malignant progression and prognosis in oligodendrogliomas. Oncotarget. 2015;6(35):38257-38269.

19. Wu G, Wilson G, Zhou G, Hebbard L, George J, Qiao L. Oct4 is a reliable marker of liver tumor propagating cells in hepatocellular carcinoma. Discov Med. 2015;20(110):219-229.

20. Cao B, Su Y, Oskarsson M, et al. Neutralizing monoclonal antibodies to hepatocyte growth factor/scatter factor (HGF/SF) display antitumor activity in animal models. Proc Natl Acad Sci U S A. 2001;98(13):7443-7448.

21. Kawaguchi M, Kataoka H. Mechanisms of hepatocyte growth factor activation in cancer tissues. Cancers (Basel). 2014;6(4):1890-1904.

22. Kara F, Yildirim A, Gumusdere M, Karatay S, Yildirim K, Bakan E. Association between hepatocyte growth factor (HGF) gene polymorphisms and serum HGF levels in patients with rheumatoid arthritis. Eurasian J Med. 2014;46(3):176-181.

23. Karabulut SF, Tas F, Akyuz F, et al. Clinical significance of serum hepatocyte growth factor (HGF) levels in hepatocellular carcinoma. Tumour Biol. 2014;35(3):2327-2333.

24. Huang FI, Chen YL, Chang CN, Yuan RH, Jeng YM. Hepatocyte growth factor activates Wnt pathway by transcriptional activation of LEF1 to facilitate tumor invasion. Carcinogenesis. 2012;33(6):1142-1148.

25. Levrero M. Viral hepatitis and liver cancer: the case of hepatitis C. Oncogene. 2006;25(27):3834-3847.

26. Sahebjada S, Schache M, Richardson AJ, Snibson G, Daniell M, Baird PN. Association of the hepatocyte growth factor gene with keratoconus in an Australian population. PLoS One. 2014;9(1):e84067.

27. Prystupa A, Kicinski P, Sak J, Boguszewska-Czubara A, TorunJurkowska A, Załuska W. Proinflammatory cytokines (il-1alpha, il-6) and hepatocyte growth factor in patients with alcoholic liver cirrhosis. Gastroenterol Res Pract. 2015;2015:532615.

28. Marin-Serrano E, Rodriguez-Ramos C, Diaz-Garcia F, Martín-Herrera L, Fernández-Gutiérrez-Del-Alamo C, Girón-González JA. Hepatocyte growth factor and chronic hepatitis c. Rev Esp Enferm Dig. 2010; 102(6):365-371.
29. Medina J, Caveda L, Sanz-Cameno P, et al. Hepatocyte growth factor activates endothelial proangiogenic mechanisms relevant in chronic hepatitis c-associated neoangiogenesis. J Hepatol. 2003;38(5): 660-667.

30. Yamagamim H, Moriyama M, Matsumura H, et al. Serum concentrations of human hepatocyte growth factor is a useful indicator for predicting the occurrence of hepatocellular carcinomas in c-viral chronic liver diseases. Cancer. 2002;95(4):824-834.

31. Daveau M, Scotte M, Francois A, et al. Hepatocyte growth factor, transforming growth factor alpha, and their receptors as combined markers of prognosis in hepatocellular carcinoma. Mol Carcinog. 2003;36(3): $130-141$.

32. Ogunwobi OO, Liu C. Hepatocyte growth factor upregulation promotes carcinogenesis and epithelial-mesenchymal transition in hepatocellular carcinoma via Akt and COX-2 pathways. Clin Exp Metastasis. 2011;28(8):721-731.

33. Hoshino K, Satoh T, Kawaguchi Y, Kuwana M. Association of hepatocyte growth factor promoter polymorphism with severity of interstitial lung disease in Japanese patients with systemic sclerosis. Arthritis Rheum. 2011;63(8):2465-2472.

34. Motone M, Katsuya T, Ishikawa K, et al. Association between hepatocyte growth factor gene polymorphism and essential hypertension. Hypertens Res. 2004;27(4):247-251.

35. Toiyama Y, Miki C, Inoue Y, Okugawa Y, Tanaka K, Kusunoki M. Serum hepatocyte growth factor as a prognostic marker for stage II or III colorectal cancer patients. Int J Cancer. 2009;125(7):1657-1662.

36. Hosoda H, Izumi H, Tukada Y, et al. Plasma hepatocyte growth factor elevation may be associated with early metastatic disease in primary lung cancer patients. Ann Thorac Cardiovasc Surg. 2012;18(1):1-7.

37. Canadas I, Taus A, Gonzalez I, et al. High circulating hepatocyte growth factor levels associate with epithelial to mesenchymal transition and poor outcome in small cell lung cancer patients. Oncotarget. 2014;5(14):5246-5256.
OncoTargets and Therapy

\section{Publish your work in this journal}

OncoTargets and Therapy is an international, peer-reviewed, open access journal focusing on the pathological basis of all cancers, potential targets for therapy and treatment protocols employed to improve the management of cancer patients. The journal also focuses on the impact of management programs and new therapeutic agents and protocols on

\section{Dovepress}

patient perspectives such as quality of life, adherence and satisfaction The manuscript management system is completely online and includes a very quick and fair peer-review system, which is all easy to use. Visit http://www.dovepress.com/testimonials.php to read real quotes from published authors. 